\title{
UNA ANÈCDOTA DEL REI JAUME I I EL SEU PARAL.LEL ÀRAB (1)
}

\author{
Per \\ SAMUEL G. ARMISTEAD \\ Universidad de California-Davis
}

La Crónica o Libre dels feyts de Jaume I, el Conqueridor -narrada en la primera persona majestàtica nós-, inclou un breu, però destacable episodi (2). En la campanya contra el regne musulmà de València, el rei Jaume establí el seu campament probablement al Puig i era a punt per a marxar sobre Borriana, però, a causa d'una oreneta que havia fet niu prop de l'extrem superior del pal de la tenda, el rei ordenà que la seua tenda es quedara plantada fins que l'ocell $i$ els seus pollets foren capaços d'anar-se'n volant:

E fom a Borriana, e, quan venc que en volguen llevar la host, una oreneta havia feit niu prop de l'escudella en lo tendal, e manam que no en llevassen la tenda tro que ella se'n fos anada sos fills, plus en nostra fe era venguda (3).

(1) Publicat en anglés ("An Anecdote of King Jaume I and its Arabic congener») dins: D. Hook-B. Taylor (eds.), Cultures in Contact in Medieval Spain: Historical and Literary Essays Presented to L.P. Harvey, London, King's College, 1990. Aquesta traducció ha estat gentilment autoritzada i revisada per l'autor del treball.

(2) Martí de Riquer compara la intervenció personal del rei Jaume en la redacció de la seua crònica amb la d'Alfons X, "tot i que l'obra històrica d'Alfons el Savi sigui molt menys personal que la de Jaume l» (Història de la literatura catalana [Barcelona: Ariel, 1980], I, 399). Vegeu també els importants comentaris de LI. Nicolau d'Olwer, "La Crònica del Conqueridor i els seus problemes", EUC, XI (1926), 79-88, en les ps. 81-83.

(3) Les quatre grans cròniques, ed. de Ferran Soldevila (Barcelona: Selecta, 1971), p. 92 (Cap. 215), o en l'edició de Josep Maria de Casacuberta, 4 vols. (Barcelona: Barcino, 1926-60), IV, 54. Sobre el rei acampat al Puig vegeu Soldevila, p. 293 a-b, n. 8. El Puig de Santa Maria correspon al cidià Cebolla, una etimologia popular castellana per a l'àrab Yubayla. Vid. Ramón Menéndez Pidal, La España del Cid, 2 vols. (Madrid: Espasa-Calpe, 1947), I, 357; Cantar de Mio Cid, 3 vols. (Madrid: Espasa-Calpe, 1944-46), II, 569-71; també Soldevila, p. 291 a-b. Avui la ciutat és coneguda simplement com «El Puig" (València, en el partit judicial de Sagunt). 
Aquesta deliciosa vinyeta ha cridat amb justícia l'atenció dels estudiosos de l'edat mitjana hispana. Martí de Riquer, recalcant l'intimisme característic de certs passatges del Libre dels feyts, observa:

Precisament el fet que el rei volgués deixar constància d'aquest fet minúscul ens deixa veure un altre aspecte de la seva personalitat, que no tot és conquerir regnes dels sarraïns, guanyar batalles i vessar coratge, sinó també tendresa envers les bestioles que s'acullen «a la fe» del monarca, com si també fossin vassalls seus (4).

Ferran Soldevila al-ludeix també a «aquest delicat episodi, que mostra la tendresa d'ànima del Conqueridor» (5), i Menéndez Pidal, comparant la història del rei Jaume amb un antic i distant incident molt semblant atribuït al Cid, al-ludeix al "delicado sentimentalismo de un rey venturoso" (6). En suggerir un exquisit interés pel destí d'animals petits $i$ indefensos, la deferència del rei Jaume envers l'oreneta i la seua niuada proporciona, fins i tot, una atractiva nota d'intimisme personal i de compassió reial. l, de fet, potser és possible que una oreneta pogués haver fet niu a la part superior del pal de la tenda del rei i s'hagués posat, així, sota la protecció reial. Però crec que l'incident va tenir en el seu origen unes altres implicacions que només poden ser enteses plenament dins d'un context islàmic.

Les primeres dues parts del Libre dels feyts (fins al capítol 327) van ser compostes probablement al voltant del 1244 (7). El gran geògraf àrab Yāqūt ibn 'Abdallāh al-Rūmī va compondre el seu vast diccionari $M u^{\circ} \hat{y} a m$ al-buldān, Diccionari dels països, entre el 1212 i la seua mort el 1229 (8). Fent referència â la conquista d'Egipte pel famós general ${ }^{\circ} \mathrm{Amr}$ ibn al- ${ }^{\circ} \bar{A} s ̦$ (o al- ${ }^{\circ} \mathrm{AșT}$ ), Yãqūt relata una història sorprenent. En conquistar la fortalesa romana de Babilònia -situada a l'actual al-Fusțāt (antecessor del Caire)-,'Amr aixeca el campament per a marxar cap al nord contra Alexandria:

I quan 'Amr [ibn al-cAșT] i els que eren amb ell havien passat a través de la fortalesa, decidí de marxar cap a Alexandria, i així viatjà cap allí en [el mes de] Rabt' I de l'any 20 A.H. (= A.D. 640). 'Amr ordenà aixecar la seua tenda (fusțaț), perà una coloma (yamāmâ) hi havia post els ous damunt, per la qual cosa va dir: «Ella és inviolable en la nostra proximitat (ŷ́iwāri$n \bar{a})$. Deixeu la tenda desplegada fins que tinga els pollets $i$, llavors, feulos volar». Així la seua tenda romangué dreçada i hi posà davant un home per a impedir que la coloma fóra molestada, i marxà cap a Alexandria, on romangué sis mesos fins que Déu l'obrí per a la seua conquista (9).

(4) Riquer, Història, p. 419.

(5) Soldevila, Les quatre grans cròniques, p. 293 a, n. 8. Vegeu també el seu comentari: «Així era de delicadament lleial l'ànima que s'amagava sota l'escora del ferreny Conqueridor" (Vida de Jaume / el Conqueridor, 2. ${ }^{a}$ ed. [Barcelona: Aedos, 1969], p. 204).

(6) Menéndez Pidal, La España del Cid, I, 276-77. En l'anècdota cidiana, la dona del cuiner del Campeador acaba d'infantar; l'heroi refusa d'aixecar el campament $\mathrm{i}$ insisteix perquè siga permés a la dona de descansar el mateix nombre de dies que era usual per a les dones dels nobles castellans. Vegeu Juan Gil de Zamora, De preconiis Hispaniae, editat per Manuel de Castro y Castro (Madrid: Universidad de Madrid, 1960), ps. 125-26.

(7) Vegeu Riquer, Història, ps. 406-7; per a més detalls vegeu Nicolau d'Olwer, "La Crònica", pp. 79-81.

(8) Sobre Yāqūt i el seu diccionari vegeu The Encyclopaedia of Islam, first edition, IV (Leiden: E. J. Brill, and London: Luzac, 1934), 1.153-54; Clément Huart, Littérature arabe (Paris: Armand Colin, 1923), ps. 301-3; Reynold A. Nicholson, A Literary History of the Arabs (Cambridge: University Press, 1953), p. 
En la delicadesa del rei Jaume envers l'oreneta l'erudició occidental ha percebut tan sols una delicada sentimentalitat. Tanmateix, des d'un punt de vista islàmic, la història essencialment idèntica de Yāqūt adquireix un significat molt específic, arrelat en una antiga tradició àrab i en una altra semítica encara més antiga. El tractament de la coloma per part de ${ }^{\circ} \mathrm{Amr}$ compleix amb una obligació gairebé sagrada: en buscar refugi a la seua tenda, l'ocell, com qualsevol altre viatger, s'ha situat sota la protecció de 'Amr. El text àrab diu: «taharramat bi-y iwāari-nā», "ella és harāam (inviolable, prohibida, sagrada) en la nostra proximitat (o veïnat)", la qual cosa implica que l'ocell s'ha convertit en $\hat{y} \bar{a} r$, és a dir, no només en un «veí» sinó també en un «client», i, a partir d'això, està completament protegit per la llei tribal. ${ }^{\circ} \mathrm{Amr}$ está moralment obligat, pel costum més estricte, a proporcionar a la coloma una protecció completa. Pel fet de donar santuari a la coloma, 'Amr, com a líder de musulmans que lluiten i es troben en perill en una terra estranya, està realitzant una important manifestació cultural: està refermant la tradició àrab (10).

La correspondència entre las frases clau de les històries catalana i àrab és notable: "pus en nostra fe era venguda» / «Ella és inviolable en la nostra proximitat» (que pot ser igualment traduïda, com fa Butler, per: «She has taken refu-

357, i, especialment, Friedrich J. Heer, Die historischen und geographischen Quellen in Jāqūt's Geographisches Wörterbuch (Strassburg: Karl J. Trubner, 1898).

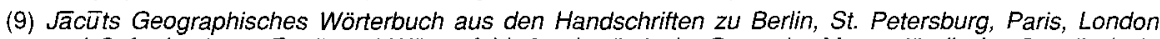
und Oxford, ed. per Ferdinand Wüstenfeld, 6 vols. (Leipzig: Deutsche Morgenländische GesellschaftF.A. Brockhaus, 1868), III, 896. L'anècdota s'esdevé a l'entrada de Yãqūt a Fusțāṭ (l'antic el Caire), i ofereix una explicació d'etimologia popular de com la ciutat rebé el seu nom: per la tenda (fusțāt) que "Amr hi deixà a causa de la coloma. Vull expresar el meu agraïment més cordial al meu amic i col.lega, el professor James T. Monroe, que generosament va localitzar per a mi el pasatge àrab; també estic en deute amb ell per la traducció inclosa ací i per les sàvies suggerències sobre el context de l'episodi. Jo vaig trobar originalment l'anècdota en una paràfrasi de Sir John Bagot Glubb, The Great Arab Conquests (New York-London: Quartet, 1980), p. 237, i, posteriorment, en Alfred J. Butler, The Arab Conquest of Egypt and the Last Thirty Years of the Roman Dominion, ed. per P.M. Fraser, 2. ed. (Oxford: Clarendon, 1978), p. 281. Pel que fa a 'Amr i a la seua conquesta d'Egipte, vegeu tambe The Encyclopaedia of Islam, 2." ed., I (Leiden: E.J. Brill, and London: Luzac, 1960), 451. L'autèntica etimologia de Fusțāt sembla ser del grec bizantí fossáton, fousáton "camp, campament" (<Llatí FOSSATUM-el foussado del Cid). Vegeu The Encyclopaedia of Islam, 2. a ed., II (Leiden: E.J. Brill, 1983), 95758; N.P. Andriotis, Etymologiko lexiko tēs koinēs neoellenikes (Atenes: Institut Français, 1951), en fousáto. Probablement, el nom de Fussātū per al districte del Yebel Nefusa a l'oest de Líbia deriva directament del llatí. Vegeu Tadeusz Lewicki, «Une langue romane oubliée de l'Afrique du Nord», Rocznik Orientalistyczny (Cracòvia), XVill (1951-52), en la p. 458.

(10) Per a la crisi experimentada per aquestes tradicions àrabs arran de la conquesta islàmica de territoris de cultura noàrab, cal tenir en compte les encertades observacions de Serafín Fanjul (trad. Al- $\hat{Y}$ ahiz, Libro de los avaros [Madrid: Editora Nacional, 1984], pp. 65-66). Son abundants les al.lusions a l'hospitatilat àrab; vegeu, per exemple, els relats detallats en Wilfred Thesiger, The Marsh Arabs (London: Longman, 1964), pp. 8-9, 122, 198-99. Edward William Lane assenyala: «Most Bedawees will suffer almost any their guests to be ill-treated while under their protection" (The Maners and Customs of the Modern Egyptians [London: J.M. Dent, and New York: E.P. Dutton, 1923], pp. 296-297). Comentant l'episodi de 'Amr a la llum de molts anys d'experiència amb els àrabs del desert, Sir John Bagot Glubb assenyala: «The tent has always been a place of refuge in the social system of the desert. To it any man or woman in want or danger could flee for protection to afford which the owner of the tent, even if a complete stranger, was bound to devote not only his best efforts but if need be his life. I have elsewhere told the story of a man who gave refuge in his tent to a sick wolf, and even killed a fellow tribesman to protect it. To us, it may seem curious that so ruthless a soldier as 'Amr ibn a nesting dove" (The Great Arab Conquests, pp. 237-238). Butler també ha assenyalat: «The appeal for protection, even on the part of an enemy, was sacred in the eyes of the Muslims" (The Arab Conquest, p. 281, n. 2). Pel que fa als temes yiwār $i \hat{y a}$ r i a les seues implicacions, vegeu The Encyclopaedia of Islam, 2. ${ }^{a}$ ed., II, 558-59. Per a la tenda com a lloc de refugi (a l'empara d'un magnat), compareu, entre les Maqāmāt del Hamadāani, la maqam de Al-Aswad (trad. W.J. Pendergast [London: Curzon Press, 1973], pp. 110112; trad. esp. Serafín Fanjul [Madrid: Alianza, 1988], pp. 105-107). 
ge under our protection"). Però mentre que l'interés de Jaume I per l'oreneta sembla ser simplement una encantadora anècdota, una indicació de la «intimitat» de la crònica i, possiblement, d'un aspecte de la personalitat del rei, la protecció de la coloma per part de ${ }^{\circ} \mathrm{Amr}$ està carregada de significat per a la seua comunitat de guerrers del desert; evoca un complet sistema de valors que són crucials per al context cultural de l'episodi. Una història és personal i incidental; l'altra és completament i ricament funcional. Aquestes característiques semblen qualificar la història àrab -alguna versió, però sens dubte no pas la de Yāqūt-com el probable antecedent genètic del seu anàleg català.

El debat actual entre individualisme-tradicionalisme ha tendit generalment a passar per alt la possibilitat d'una contribució àrab als orígens o al desenvolupament posterior de l'èpica romànica (11). La considerable atenció erudita centrada recentement en els paral.lels entre les narracions heroiques àrabs $i$ romàniques -i, especificament, espanyoles-, ha estat oblidada per l'hispanomedievalisme «convencional» (12). A més a més, un llibre recent sobre la moderna èpica popular àrab, que ha viscut en una tradició oral ininterrompuda des de l'edat mitjana i que continua sent conreada avui, tant en formes èpiques llargues (sira) com en balades breus (mawwā $)$, situa ara el problema complet en una perspectiva diferent $i$, fins i tot, més complexa (13). Les històries àrab i catalana ací tractades no es poden caracteritzar com a èpica-almenys en les formes en què ens han arribat (14)-. Però igualment, evoquen circumstàncies

(11) Són excepcions notables la recensió de L.P. Harvey de Poesia narrativa árabe y épica hispánica, de Francisco Marcos Marín (Madrid: Gredos, 1971), BHS, LI (1974), 280-283, i els seus articles «Medieval Spanish», dins: Traditions of Heroic and Epic Poetry, ed. per A.T. Hatto (London: MHRA, 1980), ps. 134164, especialment ps. 141-144, i "(A) guisado" in the Poema de Mio Cid: the ghost of a pun in Arabic?", BHS, LXII (1985), 1-6, aixi com la contribució de Brenda Fish en aquest mateix volum.

(12) Sobre els, de vegades, sorprenents paral.Jels entre la narrativa heroica àrab clàssica i l'èpica hispana, vegeu Alvaro Galmes de Fuentes, Epica árabe y épica casteliana (Barcelona: Ariel, 1977) i Francisco Marcos Marín, «El legado árabe de la épica hispánica», NRFH, XXX (1981), 396-419. També, Joan Vernet, "Antar y España», BRABL, XXXI (1965-66), 345-50. Per a d'altres treballs recents, vegeu la meua recensió de Galmés, HR, XLVIII (1980), 239-41.

(13) Sobre la moderna èpica oral àrab vegeu ara Bridget Connelly, Arabic Folk Epic and Identity (Berkeley and Los Angeles: University of California Press, 1986), que inclou una extensa revisió i bibliografia de la investigació anterior. Vegeu també Serafín Fanjul García, Literatura popular árabe (Madrid: Editora Nacional, 1977), ps. 132-46. Cal tenir en compte també la monografia de Susan Slymovics, The Merchant of Art: An Egyptian Hilāli Oral Epic Poet in Performance (Berkeley and Los Angeles: University of California Press, 1987). Per a un repertori balàdic modern (mawā $\overline{w i}$ ), que fins avui conviu amb l'antigua tradició èpico-medievals de la Hilă $T y y a$, vegeu el llibre de Pierre Cachia, Popular Narrative Ballads of Modern Egypt (Oxford: Clarendon Press, 1989) . Per a les implicacions d'aquesta coexistència èpico-balàdica, tingueu en compte el meu article «Los orígenes épicos del romancero en una perspectiva multicultural", Homenaje a Mercedes Díaz Roig (Mèxic, en premsa).

(14) La història de Yāqūt, com a exemple de futūhāt o literatura de conquesta, podria haver estat treta fácilment de la narrativa heroica oral. Sobre la relació del Libre dels feyts amb la poesia èpica catalana, vegeu Manuel de Montoliu, La cançó de gesta de Jaume I: nova teoria sobre la Crónica del Conqueridor (Tarragona: Editorial Tarragona, 1922); "Sobre els elements èpics, principalment arturians, de la Crònica de Jaume l», Homenaie a Menéndez Pidal, 3 vols. (Madrid: Hernando, 1925), I, 697-712; "Sobre la teoria dels poemes històrics i les cròniques rimades catalanes medievals", Revista de Catalunya, XXIII (1926), 401-11; «Sobre el primitiu text versificat de la Crónica de Jaume I", Anuari de l'Oficina Romànica, I (1928), 253-336; també Riquer, Història, I, 380-92, 416-18. Per als elements èpics addicionals -tant narratius com estilístics- absorbits per les cròniques catalanes, vegeu Miquel Coll i Alentorn, «Notes per a l'estudi de la influència de les cançons de gesta franceses damunt la crònica de Bernat Desclot» EUC, XII (1927), 46-58; també Josep Miquel Sobré, L'èpica de la realitat: l'escriptura de Ramon Muntaner i Bernat Desclot (Barcelona: Curial, 1978). Pel que fa a la literatura de futūhät, vegeu James T. Monroe, «The Historical Arjuza of Ibn 'Abd Rabbihi...», JAOS, XCl (1971), 6795 , en la p. 69. 
culturals que no manquen de significat per a l'estudi d'una possible contribució àrab a l'èpica espanyola -com també a d'altres formes de literatura oral vernacla-.

Fins i tot, si la història del rei Jaume està connectada amb l'àrab, sembla dubtós que el rei aragonés, o els seus col.laboradors, l'hagueren apresa precisament llegint el diccionari geogràfic de Yāqūt o cap altre relat àrab escrit (15). El que suggereixen ambdues històries és, més aviat, el ric ambient intercultural de la lbèria medieval, en la qual els motius emigrat fàcilment, de boca en boca, d'una comunitat lingüística a una altra i d'un corpus de literatura oral a un altre (16). Les circunstàncies històriques i culturals de la Península lbèrica en l'edat mitjana suggereixen que les nostres perspectives sobre el desenvolupament

(15) Butler carateritza la narrativa de Yāqüt com una «familiar story» (The Arab Conquest, p. 281, n. 2). Curiosament, tant Soldevila com Butler semblen acceptar els seus relats catalans $i$ àrabs com a històrics. En argüir que l'episodi de l'oreneta s'esdevingué al Puig, més probablement que a Borriana, Soldevila afirma: «En el poc temps que el rei estigué a Borriana, no és possible que una oreneta pogué fer-hi niu. D'altra banda, aquesta anada a Borriana devia tenir lloc, al més aviat, per l'agost, quan les orenetes ja fa temps que han fet el niu..." (Les quatre grans cròniques, p. 293 a). Igualment, quant a la història de $Y \bar{a} q \bar{u} t$ Butler anota: «It fits very well with the time of year when 'Amr left Babylon -the end of April- and it has the ring of truth" (p. 281, n. 2). Siga com siga, l'anècdota pot ser ben bé de caire tradicional. No hi ha res semblant en el Motif-Index of Folk-Literature, de Stith Thompson, 6 vols. (Bloomington: Indiana University Press, 1955-58). Tanmateix, compareu els següents motius: B365.2: Animal grateful to hero for preventing destruction of nest (sense referències incloses); N261.1: Trains of troubles for seven brothers for having destroyed bird's nest; Q285.1.2: Punishment for breaking bird's nest. A la llum dels dos últims motius, pocs dubtes pot haver-hi pel que fa a la relació de la història amb una creença popular coneguda a bastament. Vegeu José A. Sánchez Pérez, Supersticions españolas (Madrid: SAETA, 1948): «Quien destruye un nido de golondrina construido en casa de su propiedad, causará la desgracia de su familia» (p. 219); Mohammad lbn Azzuz Akím, Diccionario de supersticiones y mitos marroquies (Madrid: CSIC, 1958): «Será desgraciado quien destruya el nido de una golondrina» (p. 39); Popualr Beliefs and Superstitions: $A$ Compendium of American Folklore from the Ohio Collection of Newbell Niles Puckett, ed. per Wayland D. Hand et al., 3 vols. (Boston: G.K. Hall, 1981): clf birds build a nest under the eaves of your house, do not destroy the nest, because it is good luck to have them there» (n. 0 30.494); celf yoy move a sparrow's nest, it's bad luck" (30.568); Popular Beliefs, ed. per W.D. Hand i Jeannine E. Talley (Salt Lake City: University of Utah Press, 1984): clf you tear down a bird's nest, you'll have bad luck" (n. 12.224). A la inversa, la presència del niu d'un ocell en la teulada (o simplement prop) de la casa d'algún és àmpliament considerada com a portadora de bona sort: Hand et al., Ohio, núms. 30.491, 30.493, 30.580; Harry M. Hyatt, Folklore from Adams County Illinois (New York: Alma Egan Hyatt Fundation, 1935), n.2 1.528. Per a més informació sobre el tema, vegeu Eduard Hoffmann-Krayer i Hanns Bächtold-Stäubli, Handwörterbuch des deutschen Aberglaubens, 10 vols. (New York: Walter De Gruyter, 1987), en Schawalbennest, Vogelnest. L'oreneta, com en la història del rei Jaume, és particularment portadora de bona sort. Coneguda en la parla regional alemanya com Muttergottesvogel Herrgottsvöglein, l'oreneta i el seu niu ofereixen una gran varietat de proteccions: «Algemein ist der Glaube, das die S [schawalbe] dans Haus, an dem sie nistet, vor Blitz, Streit, und Tod bewahrt» (Oswald A. Erich i Richard Beitl, Wörterbuch der deutschen Volkskunde, 2." ed. (Stuttgart: Alfred Kröner, 1955), vegeu Schwalbe). En un context hispànic: "La casa en que anidan [las golondrinas], es por este hecho afortunada" (Sánchez Pérez, p. 145); «En las casas donde anidan las golondrinas, nunca hay disturbios ni desgracias» (Félix Coluccio, Diccionario de creencias y supersticiones largentinas y americanas] [Buenos Aires: Corregidor, 1983], p. 206). Ibn Azzuz Akím esmenta idèntiques creences al Marroc (pp. 29-30); també: "There is baraka in the swallow... They bring good luck to the house in which they nest" (Edward Westermarck, Ritual and Belief in Marocco, 2 vols. [New Hyde Park, New Yord: University Books, 1968], II, 340; així mateix, Survivances paiennes dans la civilisation mahométane [Paris: Payot, 1935], p. 135).

(16) Circumstàncies semblants envolten sens dubte la creació, o, millor, re-creació, a Castella de certes històries per part de Don Juan Manuel -per esementar-ne només un exemple-. Vegeu John England, "¿Et non el dia del lodo?: the structure of a story in El Conde Lucanor", i Celia Wallhead Munera, "Three Tales from El Conde Lucanor and their Arabic Counterparts», ambdós dins Juan Manuel Studies, ed. per lan Macpherson (London: Tamesis, 1977), ps. 69/86 i 101-117. Munera escriu: «There are no important verbal parallels which suggests that Don Juan was recalling a tale in his own words rather working from written models" (p. 117). Alan D. Deyermond ha assenayalat: "No se debe pasar 
de la literatura medieval hispànica -i de l'èpica en particular- no poden estar completes a no ser que, almenys, la possibilitat d'aquests intercanvis siga tinguda en compte i, quan serà l'hora, explorada exhaustivament (17).

Oferesc aquesta breu nota, com a expressió de sincera amistat i d'admiració illimitada, al professor L. Patrick Harvey, l'exemplar erudició del qual tant ha fet per a il.luminar els contactes culturals entre Hispània i el món islàmic.

por alto la posibilidad de una influencia árabe directa en algunos casos... ¿Es necesario, pues, pensar en fuentes árabes escritas, mientras que las fuentes europeas fueron orales? No lo creo" (Libro del Conde Lucanor, estudi preliminar d'Alan Deyermond, edició modernitzada i notes de Reinaldo Ayerbe-Chaux, Clásicos Modernizados Alhambra, II [Madrid: Alhambra, 1985], p. 28). Per a una revisió dels estudis sobre els contactes literaris hispano-àrabs, vegeu James T. Monroe, The Art of Bad $T^{-}$az-Zama $n$ al-Hamadha $n \Gamma$ as Picaresque Narrative (Beirut: American University, 1983), ps. 912.

(17) Per a un avanç recent en aquesta direcció, vegeu María Rosa Menocal, The Arabic Role in Medieval Literary History (Philadelphia: University of Pennsylvania Press, 1987). Igualment, Francisco Márquez Villanueva, "La Celestina as Hispano-Semitic Anthropology» RLC, LXI (1987), 425-53 (trad. esp. SAA, 8 [1991], 269-292); S.G. Armistead i James T. Monroe, «Celestina's Muslim Sisters", Celestinesca, XIII: 2 (1989), 3-27. 